\title{
Does subcutaneous administration of recombinant human erythropoietin increase thrombotic events in total hip arthroplasty? A prospective thrombelastography analysis
}

Ru-xin Ruan, Chao-wen Bai, Le Zhang, Chao-ran Huang, Sheng Pan, Xing-chen Zhang, Zheng-ya Zhu, Xin Zheng ${ }^{*}$ and Kai-jin Guo ${ }^{*}$ (D)

\begin{abstract}
Background: Anemia is one of severe complications in the perioperative period of total hip arthroplasty (THA). Erythropoietin (EPO) has been considered to improve patients' anemia state, but its efficiency and safety remains controversial.

Methods: A total of 152 patients who underwent total hip arthroplasty from January 2017 to March 2019 were randomized to 2 groups. Recombinant human erythropoietin (rHu-EPO) group was treated with rHu-EPO subcutaneous injection $10000 \mathrm{IU}$ after operation and once daily in the next week, while control group was treated with none extra treatment. Routine hematologic examination and thrombelastography (TEG) performed at different time point respectively. Doppler ultrasound for bilateral lower limbs was performed 1 day before surgery and 7 days after surgery. Auxiliary examination outcomes, blood transfusions outcomes, and postoperative complications were recorded as assessment indicators.
\end{abstract}

Results: The difference in the relevant indexes of traditional coagulation and TEG values between two groups were not significantly. No significant difference was observed in the incidence of thromboembolism events and other complications between two groups during postoperative period. The amount of intraoperative blood loss was similar between the two groups. However, the postoperative use and dosage of allogeneic blood in the rHu-EPO group were lower than those in the control group. The hemoglobin and hematocrit level in the rHu-EPO group were higher than that in the control group after surgery.

Conclusion: Postoperative subcutaneous injection of rHu-EPO can improve hematological anemia-related parameters, reduce the use and dosage of allogeneic blood transfusions (ABTs), and has no significant influence on the formation of thrombosis and other complications in patients undergoing total hip arthroplasty in short term.

Keywords: Recombinant human erythropoietin, Total hip arthroplasty, Thrombotic events, Thrombelastography, Perioperative anemia

\footnotetext{
* Correspondence: thindy1980@163.com; kaiijinguo@163.com

Department of Orthopaedics, The Affiliated Hospital of Xuzhou Medical University, No. 99, Huaihai West Road, Xuzhou, Jiangsu Province 221000, China
}

(c) The Author(s). 2020 Open Access This article is licensed under a Creative Commons Attribution 4.0 International License, which permits use, sharing, adaptation, distribution and reproduction in any medium or format, as long as you give appropriate credit to the original author(s) and the source, provide a link to the Creative Commons licence, and indicate if changes were made. The images or other third party material in this article are included in the article's Creative Commons licence, unless indicated otherwise in a credit line to the material. If material is not included in the article's Creative Commons licence and your intended use is not permitted by statutory regulation or exceeds the permitted use, you will need to obtain permission directly from the copyright holder. To view a copy of this licence, visit http://creativecommons.org/licenses/by/4.0/ The Creative Commons Public Domain Dedication waiver (http://creativecommons.org/publicdomain/zero/1.0/) applies to the data made available in this article, unless otherwise stated in a credit line to the data. 


\section{Introduction}

Total hip arthroplasty (THA) is considered to be distinctly advantageous for various end-staged hip diseases $[1,2]$. Perioperative anemia is a common problem in major orthopedic surgery, concerning approximately 15 to $25 \%$ of patients in the preoperative period and as much as $80 \%$ in the postoperative period [3]. Patients undergoing THA are always plagued with anemia due to blood loss [4] and perioperative anemia may lead to an increased morbidity and mortality [5]. Additional allogenic blood transfusions (ABTs) are an effective method to improve anemia state but could increase risks of virus transmission, transfusion reactions, and possible immunosuppression [6,7]. Therefore, plenty of strategies are used in the perioperative period of THA to reduce $\mathrm{ABT}$ requirements and the application of hematopoietic agents has proven effective [8-10].

Erythropoietin (EPO) is one of the erythropoiesisstimulating drugs, which promotes hematopoietic stem cells differentiate into red blood cell to improve the anemia state of patients. Its artificial synthetic recombinant human erythropoietin ( $\mathrm{rHu}-\mathrm{EPO})$ is used clinically as exogenous human erythropoietin and has similar function with EPO. The benefits of perioperative use of $\mathrm{rHu}-\mathrm{EPO}$ in major orthopedic procedures have been well established $[11,12]$. The major misgiving is the application of rHu-EPO could cause venous thromboembolism (VTE). In a small-scale, double-blind, placebocontrolled study, EPO increases the incidence of thrombosis by $15 \%$ among healthy male volunteers [13]. However, studies associated with the effect of $\mathrm{rHu}-\mathrm{EPO}$ on coagulation function of patients undergoing THA are still lacking.

Nowadays, traditional plasma-based coagulation test is routinely used to monitor the perioperative clotting status of patients with THA [14]. Compared with traditional coagulation test, thrombelastography (TEG) evaluates the whole process of blood coagulation as a continuous graph from the beginning of clot formation to fibrinolysis and has a higher sensitivity on detecting abnormal blood state. This technique has been gradually used in orthopedic surgery to direct individualized anticoagulant therapy $[15,16]$.

In this study, we used TEG to evaluate the safety of $\mathrm{rHu}-\mathrm{EPO}$ in combination with routine coagulation tests and color Doppler ultrasound at different times during perioperative period. The other purpose of this study is to reconfirm the efficacy of rHu-EPO subcutaneous administration on improving patients' anemia state.

\section{Materials and methods}

\section{Patient selection and study design}

After the hospital ethics committee approval, a prospective and randomized-controlled study was conducted in patients undergoing cementless unilateral primary THA from January 2017 to March 2019. Every participator enrolled was given a written, informed consent. Patients who were 18 years or older and diagnosed as osteoarthritis or osteonecrosis of femoral head were recruited in this study. Patients were excluded if they (1) were contraindicated to $\mathrm{rHu}-\mathrm{EPO}$; (2) had lower extremity deep venous thrombosis (DVT), pulmonary embolism or myocardial infarction and receive anticoagulant therapy or antiplatelet treatment recently; (3) had severe liver diseases, uncontrolled hypertension, clinically significant impairment of renal function, or any other organ insufficiencies; (4) preoperative $\mathrm{Hb}<90 \mathrm{~g} / \mathrm{l}$; (5) had a history of hip fracture or required additional osteotomy during THA. Finally, 152 patients were meeting the inclusion criteria and randomized into 2 groups. The patients' characteristics details were shown in Table 1.

\section{Surgical approach and perioperative managements}

All THAs were performed through a posterolateral incision by the same surgeon under general anesthesia. Patients in both groups received a $15 \mathrm{mg} / \mathrm{kg}$ loading dose intravenous infusion tranexamic acid $30 \mathrm{~min}$ before incision and the same dose $3 \mathrm{~h}$ after closing the incision. A drainage tube was used in the first $24 \mathrm{~h}$ after operation and retrieved on the morning of day 2 postoperatively. Color Doppler ultrasound of both lower limbs was performed in all patients 1 day before the surgery and postoperative day 7 (POD 7) to screen for DVT. Intravenous iron supplementation was administered in combination with $\mathrm{rHu}-\mathrm{EPO}$. Patients in the $\mathrm{rHu}-\mathrm{EPO}$ group received $10000 \mathrm{IU}$ of $\mathrm{rHu}-\mathrm{EPO}$ injections (Epogen, Sansheng, Shenyang, China) subcutaneously and $200 \mathrm{mg}$ iron sucrose (Ferrous Saccharose, Hengsheng, Nanjing, China) diluted with $250 \mathrm{ml}$ normal saline intravenously 3 hours after the operation. The same dose of subcutaneous injections rHu-EPO was given once daily and intravenous iron sucrose was given on every other day within a week (POD 2, POD 4, and POD 6). Hb, HCT, and platelet count were examined on preoperative day 1, POD 1 ,

Table 1 Baseline characteristics of patients

\begin{tabular}{llll}
\hline & $\begin{array}{l}\text { rHu-EPO group } \\
(\boldsymbol{n}=\mathbf{7 4})\end{array}$ & $\begin{array}{l}\text { Control group } \\
(\boldsymbol{n}=\mathbf{7 8})\end{array}$ & $\boldsymbol{P}$ value \\
\hline Age (years) & $66.2 \pm 10.9$ & $65.7 \pm 9.1$ & 0.773 \\
Female sex & $44(59.5 \%)$ & $40(51.3 \%)$ & 0.311 \\
Weight $(\mathrm{kg})$ & $65.9 \pm 7.3$ & $65.5 \pm 9.1$ & 0.805 \\
Body mass index $\left(\mathrm{kg} / \mathrm{m}^{2}\right)$ & $23.8 \pm 3.7$ & $23.7 \pm 3.6$ & 0.958 \\
Harris score & $44.84 \pm 11.87$ & $43.53 \pm 10.90$ & 0.479 \\
Comorbidity & & & \\
$\quad$ Hypertension & $39(52.7 \%)$ & $45(57.7 \%)$ & 0.625 \\
Diabetes mellitus & $3(4.1 \%)$ & $9(11.5 \%)$ & 0.132 \\
\hline${ }^{*} \boldsymbol{P}<0.05$ & & &
\end{tabular}


POD 4, and POD 7. Traditional coagulation test and TEG (TEG model 5000, Haemoscope Corporation, USA) were examined on preoperative day 1, POD 1 and POD 7. Ten milligrams of rivaroxaban were prescribed (Xarelto, Bayer, Leverkusen, Germany) orally daily as postoperation anticoagulant prophylaxis and the anticoagulant treatment lasted for a minimum of 35 days. The same rehabilitation treatments containing intravenous prophylactic antibiotics, wound care, and early functional exercises were provided equally to all patients during the stay in hospital.

\section{Transfusion protocol}

A common restrictive transfusion protocol was established. All patients with any $\mathrm{Hb} \leq 70 \mathrm{~g} / \mathrm{L}$ received $\mathrm{RBC}$ transfusions independently of symptoms. Patients with hemoglobin ( $\mathrm{Hb})$ level ranging from 71 to $100 \mathrm{~g} / \mathrm{L}$ received red blood cells (RBC) transfusions depended on the clinical symptoms of anemia or uncontrolled hypovolemia (hypotension, tachycardia, tachypnea, dizziness, etc.). $1 \mathrm{U}$ RBC was given for each transfusion until the $\mathrm{Hb}>90 \mathrm{~g} / \mathrm{L}$ or the acute anemia symptoms disappeared. We reexaminated these patients and decided to give another transfusion on the basis of their $\mathrm{Hb}$ level and clinical symptoms. No patient donated or received autologous blood.

\section{Outcome measures}

The primary outcomes were the hematological parameters of routine coagulation test and TEG. Routine blood examination and transfusion outcomes like the number of patients transfused and the number of transfusions per patient were recorded as secondary outcomes. Thromboembolism events and other complications(periprosthetic joint or superficial wound infections, large subcutaneous ecchymosis, fatigue and dizziness, etc.)were also noted.

\section{Statistical analysis}

The Kolmogorov-Smirnov test was used to determine whether measured and calculated parameters were normally distributed. Continuous variables were expressed as means \pm standard deviations. Categorical variables were described using counts and percentages. Continuous variables between $\mathrm{rHu}-\mathrm{EPO}$ and control groups were compared using independent-samplest test. Overall differences in the continuous variables at different time points were assessed by one-way analysis of variance. Pearson's chi-squared test or Fisher's exact test was used to compare the proportion of categorical variables, as appropriate. All of the data were statistically analyzed using SPSS 20.0 software (IBM Corp, Armonk, New York, USA). $P<0.05$ was considered as statistically significant.

\section{Results}

Patient demographics

A total of 202 patients were evaluated for eligibility. Of these, 33 patients' $\mathrm{Hb}$ were inferior to the minimum value of the admittance. Seven patients had a history of VTE and received anticoagulant therapy recently and 6 patients has liver or kidney insufficiency. Finally, 156 patients met the inclusion criteria and were randomized into the rHu-EPO group and the control group according to a computer-generated random sequence. In addition, 2 patients appearing hypertension and headaches after first dose of rHu-EPO and 1 patient suffering from gastrointestinal symptoms after receiving intravenous iron were excluded. Only one patient in control group withdrew the consent for private excuse during the whole trail (Fig. 1).

\section{Parameters of blood coagulation test}

D-dimer and FDP increased significantly after the procedure. The mean APTT and PT had a highest mean value on POD 1. The values would then shorten but remain higher than that in preoperative period. Nevertheless, no significant differences in D-dimer, FDP, APTT, PT, TT, FIB, and INR were observed between the two groups at different time points (Table 2).

\section{TEG assessment}

Change of TEG parameters during perioperative period was shown in Table 3. In general, hypercoagulability appears during perioperative period. $K$ value kept decreasing until POD7. Postoperative Alpha value was higher than the preoperative period and reached the maximum value on POD7. MA value is lowest on POD 1 and then increasing, even higher than preoperative period. However, there were no statistically significant differences in TEG variables we recorded between the two groups on POD1 and POD7.

\section{The risk of VTE and other complications}

Three patients in the control group and 5 patients in the $\mathrm{rHu}-\mathrm{EPO}$ group were detected to have DVT. The proportion of thromboembolic events in the rHu-EPO group (6.4\%) was not significantly different from that in the control group $(4.1 \%)(P>0.05)$. One patient in control group had a high fever after received ABT and subsided after the administration of sensitive antibiotics. Other notable complications were not found among these patients.

\section{Change of hemoglobin level and platelet count}

In Table 4, indexes associated with blood cells in the two groups decreased significantly on the first day after surgery. $\mathrm{Hb}$ and HCT on POD 4 and POD 7 were lower than that on POD 1 among all patients and were lowest 


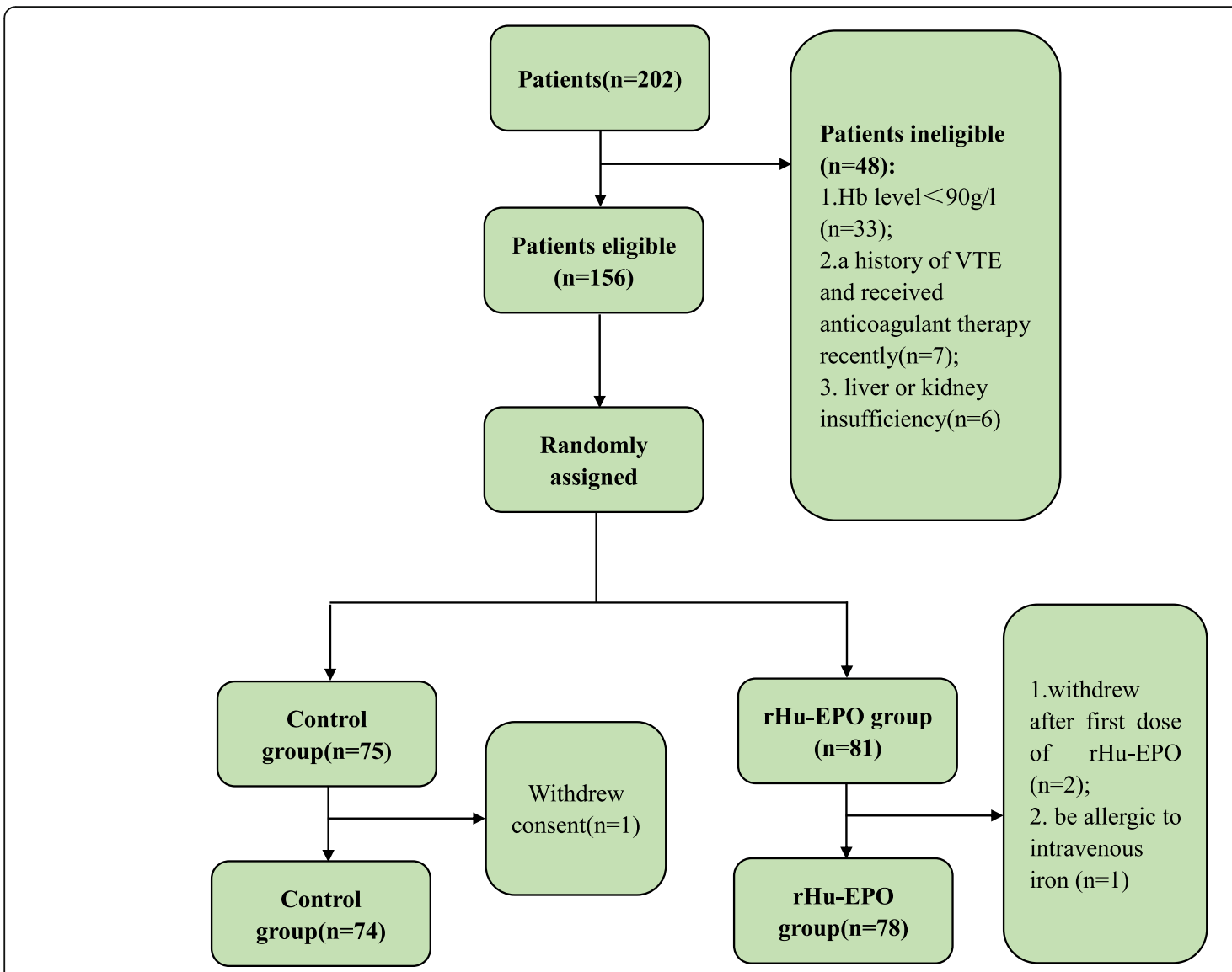

Fig. 1 The flow chart of patient enrollment

Table 2 Traditional coagulation assessment at different time points

\begin{tabular}{|c|c|c|c|c|}
\hline Indexes & Time points & rHu-EPO group $(n=74)$ & Control group $(n=78)$ & $P$ value \\
\hline $\mathrm{FDP}(\mathrm{mg} / \mathrm{l})$ & $\begin{array}{l}\text { Pre-op } \\
\text { POD1 } \\
\text { POD7 }\end{array}$ & $\begin{array}{l}3.38 \pm 1.16 \\
13.34 \pm 9.85 \\
15.09 \pm 3.97\end{array}$ & $\begin{array}{l}3.47 \pm 2.01 \\
15.95 \pm 14.00 \\
16.16 \pm 4.25\end{array}$ & $\begin{array}{l}0.727 \\
0.189 \\
0.110\end{array}$ \\
\hline D-dimer(ng/ml) & $\begin{array}{l}\text { Pre-op } \\
\text { POD1 } \\
\text { POD7 }\end{array}$ & $\begin{array}{l}1.18 \pm 0.54 \\
4.08 \pm 1.75 \\
4.77 \pm 1.70\end{array}$ & $\begin{array}{l}1.22 \pm 0.74 \\
4.47 \pm 2.33 \\
5.33 \pm 2.42\end{array}$ & $\begin{array}{l}0.710 \\
0.241 \\
0.105\end{array}$ \\
\hline PT(s) & $\begin{array}{l}\text { Pre-op } \\
\text { POD1 } \\
\text { POD7 }\end{array}$ & $\begin{array}{l}11.64 \pm 0.74 \\
12.83 \pm 1.14 \\
12.24 \pm 1.16\end{array}$ & $\begin{array}{l}11.85 \pm 0.95 \\
13.05 \pm 0.85 \\
12.54 \pm 1.06\end{array}$ & $\begin{array}{l}0.141 \\
0.163 \\
0.099\end{array}$ \\
\hline APTT(s) & $\begin{array}{l}\text { Pre-op } \\
\text { POD1 } \\
\text { POD7 }\end{array}$ & $\begin{array}{l}28.61 \pm 3.34 \\
31.80 \pm 5.71 \\
28.97 \pm 3.41\end{array}$ & $\begin{array}{l}28.81 \pm 3.63 \\
33.30 \pm 5.48 \\
30.02 \pm 3.50\end{array}$ & $\begin{array}{l}0.720 \\
0.098 \\
0.063\end{array}$ \\
\hline$\Pi(\mathrm{s})$ & $\begin{array}{l}\text { Pre-op } \\
\text { POD1 } \\
\text { POD7 }\end{array}$ & $\begin{array}{l}16.98 \pm 0.93 \\
15.86 \pm 1.05 \\
15.55 \pm 0.77\end{array}$ & $\begin{array}{l}17.24 \pm 1.29 \\
16.20 \pm 1.22 \\
15.79 \pm 0.97\end{array}$ & $\begin{array}{l}0.161 \\
0.069 \\
0.094\end{array}$ \\
\hline $\mathrm{FIB}(\mathrm{g} / \mathrm{l})$ & $\begin{array}{l}\text { Pre-op } \\
\text { POD1 } \\
\text { POD7 }\end{array}$ & $\begin{array}{l}3.52 \pm 1.09 \\
3.64 \pm 1.01 \\
4.82 \pm 1.00\end{array}$ & $\begin{array}{l}3.31 \pm 0.95 \\
3.84 \pm 0.84 \\
5.01 \pm 1.03\end{array}$ & $\begin{array}{l}0.204 \\
0.176 \\
0.268\end{array}$ \\
\hline INR & $\begin{array}{l}\text { Pre-op } \\
\text { POD1 } \\
\text { POD7 }\end{array}$ & $\begin{array}{l}1.01 \pm 0.08 \\
1.13 \pm 0.17 \\
1.06 \pm 0.10\end{array}$ & $\begin{array}{l}1.03 \pm 0.084 \\
1.15 \pm 0.11 \\
1.09 \pm 0.09\end{array}$ & $\begin{array}{l}0.062 \\
0.261 \\
0.066\end{array}$ \\
\hline
\end{tabular}

${ }^{*} P<0.05$, Pre-op pre-operation, $P O D 1$ postoperative day 1, POD7 postoperative day $7, F D P$ fibrin degradation products, $P T$ prothrombin time, APTT activated partial thromboplastin time, $\Pi$ thrombin time, FIB fibrinogen, INR international normalized ratio 
Table 3 Assessment of TEG at different time points

\begin{tabular}{lllll}
\hline Indexes & Time points & rHu-EPO group $(\boldsymbol{n}=\mathbf{7 4})$ & Control group $(\boldsymbol{n}=\mathbf{7 8})$ & $\boldsymbol{P}$ value \\
\hline $\mathrm{R}(\mathrm{min})$ & Pre-op & $5.95 \pm 1.71$ & $5.98 \pm 1.37$ & 0.886 \\
& POD1 & $5.73 \pm 2.04$ & $5.62 \pm 1.48$ & 0.695 \\
& POD7 & $5.49 \pm 1.39$ & $5.66 \pm 1.14$ & 0.403 \\
$\mathrm{~K}(\mathrm{~min})$ & Pre-op & $2.12 \pm 0.77$ & $2.39 \pm 1.05$ & 0.072 \\
& POD1 & $2.11 \pm 1.08$ & $2.31 \pm 1.27$ & 0.283 \\
& POD7 & $1.77 \pm 0.47$ & $1.60 \pm 0.65$ & 0.069 \\
Alpha $\left({ }^{\circ}\right)$ & Pre-op & $59.61 \pm 6.36$ & $59.05 \pm 11.05$ & 0.704 \\
& POD1 & $63.03 \pm 10.65$ & $61.77 \pm 10.73$ & 0.468 \\
& POD7 & $66.01 \pm 7.31$ & $66.80 \pm 8.67$ & 0.545 \\
$\mathrm{MA}(\mathrm{mm})$ & Pre-op & $60.08 \pm 5.77$ & $59.01 \pm 5.67$ & 0.254 \\
& POD1 & $57.31 \pm 7.46$ & $58.37 \pm 6.17$ & 0.341 \\
& POD7 & $64.10 \pm 2.13$ & $65.11 \pm 7.88$ & 0.286 \\
$\mathrm{Cl}$ & Pre-op & $-0.43 \pm 1.54$ & $-0.66 \pm 2.86$ & 0.540 \\
& POD1 & $-0.48 \pm 3.42$ & $-0.32 \pm 2.70$ & 0.746 \\
& POD7 & $0.73 \pm 0.63$ & $0.90 \pm 2.00$ & 0.492 \\
\hline
\end{tabular}

${ }^{*} P<0.05$, Pre-op pre-operation, $P O D 1$ postoperative day $1, P O D 7$ postoperative day $7, R$ reaction time, $M A$ maximum amplitude, $C l$ coagulation index

on POD $4(P<0.05)$ as shown in Figs. 2 and 3. The change indicated patients had a recessive blood loss during postoperative period. Compared with the control group, patients in the $\mathrm{rHu}$-EPO group had higher $\mathrm{Hb}$ and HCT level at each postoperative time point. Platelet count was lowest on POD 4 and then increased, even higher than preoperative state (Fig. 4).

\section{Requirements of allogenic blood}

The amount of intraoperative blood loss was similar between the two groups. The rate of ABT was 23.1\% (18 of 78 patients) in the control group and 9.5\% (7 of 74 patients $)$ in the rHu-EPO group $\left(P=0.029^{*}\right)$. The mean volume of allogeneic blood required among patients who needed transfusion was $1.86 \pm 0.69 \mathrm{U}$ in $\mathrm{rHu}-\mathrm{EPO}$ group and $3.50 \pm 1.95 \mathrm{U}$ in control group $\left(P=0.042^{*}\right)$.

\section{Discussion}

THA is associated with considerable blood loss and the subsequent need for ABTs [17]. Perioperative bleeding ranges from 900 to $1200 \mathrm{~mL}$ in primary THAs and leads to an apparent drop in the Hb level [18]. In our study, we found a higher level of anemia-related indexes and less exposure to ABT in the rHu-EPO group compared with patients in control group. Consistent with previous studies [19-21], this result further demonstrated $\mathrm{rHu}$ $\mathrm{EPO}$ can minimize the need for $\mathrm{ABT}$ and decrease the average required volume of $\mathrm{ABT}$ after THA. We also recorded the change of routine coagulation and TEG parameters and found that hypercoagulability develops during the perioperative period. However, no significant difference of routine coagulation and TEG parameters were observed between rHu-EPO group and control group and the incidence of VTE between two groups was similar.

EPO is a hypoxia-induced hormone produced by the kidney and fetal liver which can stimulate hematopoiesis in the bone marrow. Since obtained Food and Drug Administration (FDA) license for clinical use, EPO and its analogs $\mathrm{rHu}$-EPO have been used for treatment of the anemias caused by chronic renal failure, malignancies and proved to be effective $[22,23]$. In recent years, EPO has captured the attention of surgeons for its excellent efficacy in improving perioperative anemia caused by massive blood loss [24].

Table 4 Routine blood examination indexes at different time points

\begin{tabular}{lllll}
\hline Indexes & Time points & rHu-EPO group $(\boldsymbol{n}=\mathbf{7 4})$ & Control group $(\boldsymbol{n}=\mathbf{7 8})$ & $\boldsymbol{P}$ value \\
\hline $\mathrm{Hb}(\mathrm{g} / \mathrm{l})$ & Pre-op & $130.03 \pm 15.15$ & $129.31 \pm 14.29$ & 0.764 \\
& POD1 & $104.90 \pm 12.09$ & $99.05 \pm 13.42$ & $0.006^{*}$ \\
& POD4 & $99.14 \pm 8.81$ & $87.56 \pm 9.44$ & $<0.001^{*}$ \\
$\mathrm{HCT}(\%)$ & POD7 & $104.47 \pm 10.38$ & $95.88 \pm 10.56$ & $<0.001^{*}$ \\
& Pre-op & $39.07 \pm 4.70$ & $37.83 \pm 4.65$ & 0.103 \\
& POD1 & $31.74 \pm 3.82$ & $29.72 \pm 4.01$ & $0.002^{*}$ \\
& POD4 & $30.34 \pm 2.56$ & $26.10 \pm 2.25$ & $<0.001^{*}$ \\
$\mathrm{PLT}\left(10^{9} / \mathrm{l}\right)$ & POD7 & $31.65 \pm 3.71$ & $28.70 \pm 3.48$ & $<.001^{*}$ \\
& Pre-op & $222.68 \pm 78.43$ & $218.37 \pm 61.95$ & 0.707 \\
& POD1 & $191.60 \pm 64.59$ & $184.00 \pm 68.96$ & 0.485 \\
& POD4 & $233.08 \pm 65.06$ & $224.01 \pm 61.27$ & 0.378 \\
& POD7 & $290.42 \pm 84.46$ & $278.82 \pm 71.58$ & 0.362 \\
\hline
\end{tabular}

${ }^{\bar{*} P}<0.05$, Pre-op pre-operation, POD1 postoperative day 1, POD7 postoperative day 7, RBC red blood cell, $H b$ hemoglobin, $H C T$ hematocrit, $P L T$ platelet 


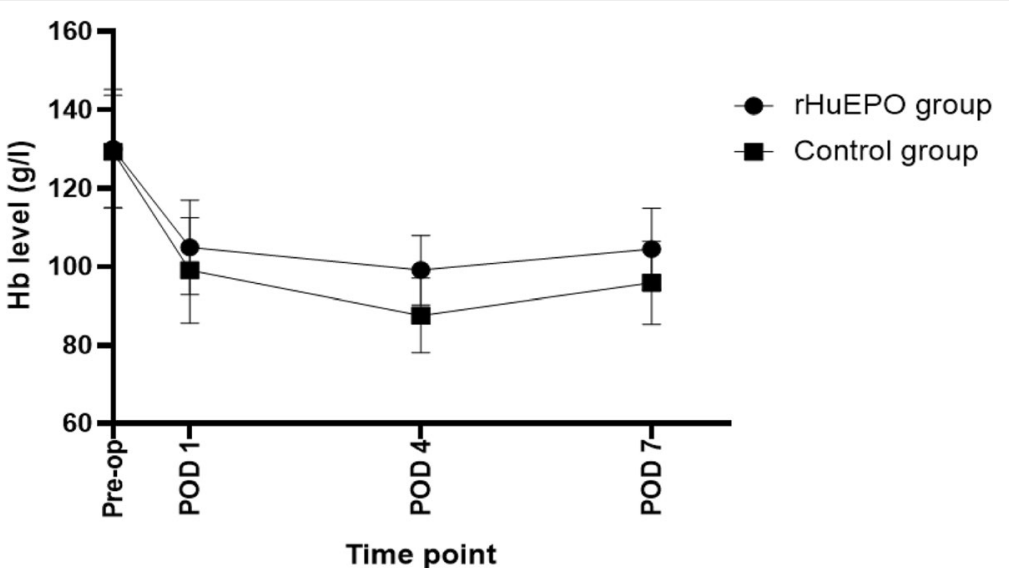

Fig. $2 \mathrm{Hb}$ level at different time point

The main concern in regard to $\mathrm{rHu}-\mathrm{EPO}$ and other hematopoietic agents is the potentially increased risk of thrombotic events because the increased RBC could affect patients' blood viscosity and hemodynamics [2528]. No association was found between EPO administration and thromboembolic events according to a randomized, controlled trail [29]. It is hypothesized that the perioperative application of EPO does not increase the risk of VTE. The increased number of RBC may not reach the extent to VTE as patients were in an anemia status themselves after THA. However, the clotting function of patients undergoing THA with the administration of rHu-EPO still needs to be explored. Therefore, we combined traditional coagulation test with TEG to monitor perioperative blood hypercoagulability.

The significant increase of D-dimer and FDP suggested that postoperative patients had a higher blood coagulation than before. The $R$ value represents the activity of coagulation factors in intrinsic and extrinsic pathways and has high significant relevance to APTT and PT. Van et al. [30] considered patients with postoperative DVT have shorter $R$ value than patients without DVT because of the activation of coagulation factors at the beginning after operation. We did find postoperative $R$-time was shorter than preoperative $R$-time but no significant difference was found between the two groups, indicating that exogenous $\mathrm{rHu}-\mathrm{EPO}$ injection did not affect coagulation factors. In the present study, $K$ value and alpha angle reflect the clotting rate and linearly correlate with FIB [31]. FIB is an essential blood clotting protein, which in high does is an indicator of future VTE. These three values were changing toward a high coagulation trend but no statistically significant difference was found between the two groups on POD 1 and POD7, indicating that exogenous $\mathrm{rHu}-\mathrm{EPO}$ injection had fewer influence on fibrinogen.

MA value is mainly related to the number and functional status of platelets and its change was basically consistent with platelet count according to previous experimental result [31]. Both of MA and PLT decreased

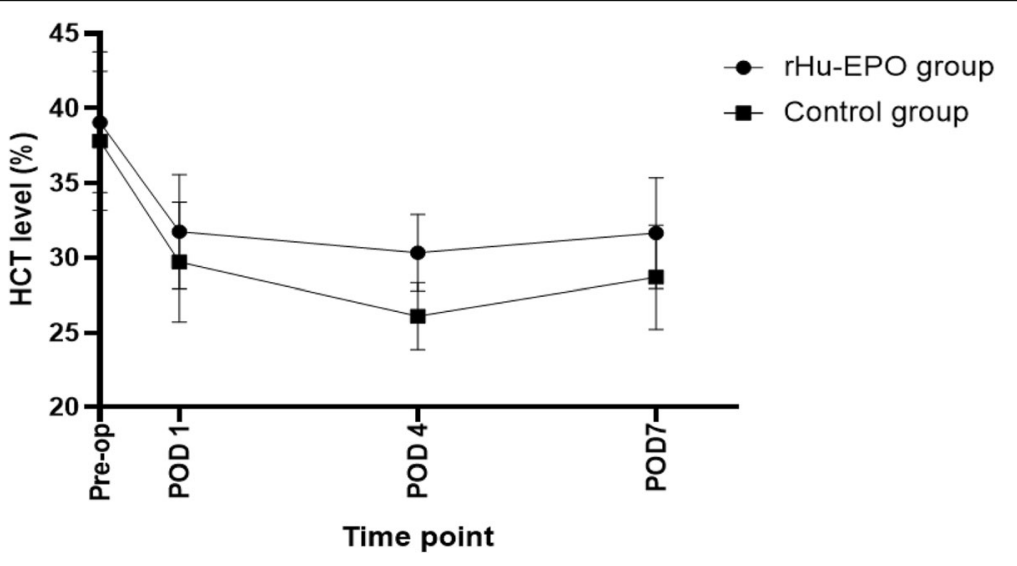

Fig. $3 \mathrm{HCT}$ level at different time point 


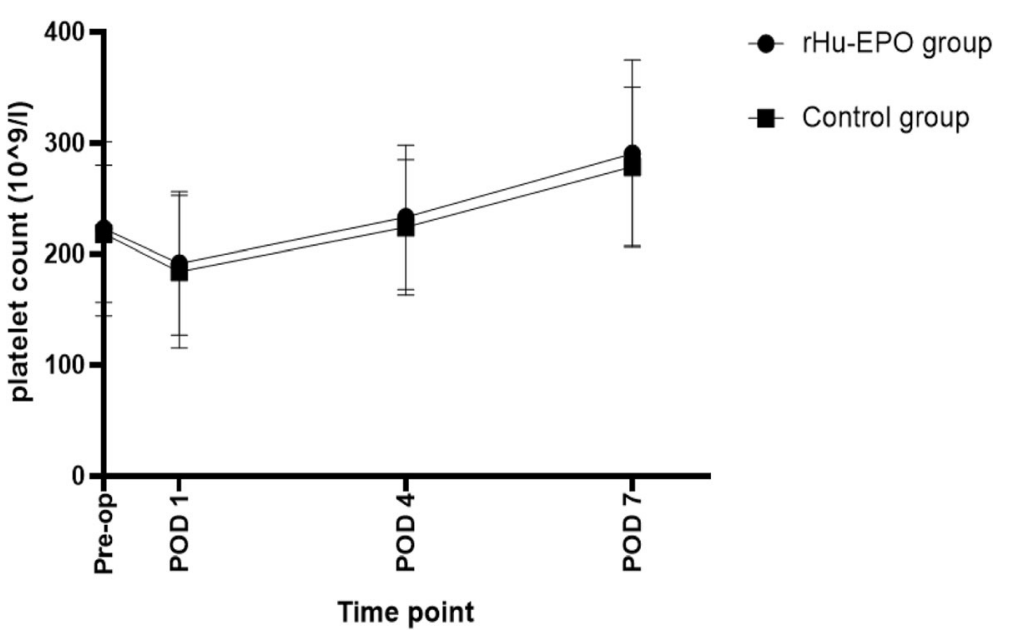

Fig. 4 Platelet count at different time point

in the first few days after operation, and then rebound, even higher than the preoperative level on POD7. It is related to the activation of platelet at later stage after operation, but the difference between two groups was not significant. Cotton et al. [32] believed that MA value could predict pulmonary embolism. When the MA value $>65 \mathrm{~mm}$, the probability of pulmonary embolism increased by 3.5 times. MA values of the control group and the $\mathrm{rHu}$-EPO group were $(65.11 \pm 7.88) \mathrm{mm}$ and $(64.10 \pm 2.13) \mathrm{mm}$ on POD 7 respectively. Therefore, patients remained in a hypercoagulable state after THA. We used oral rivaroxaban as a preventative anticoagulant therapy and the treatment would prolong to 3 months for patients with DVT. Under this anticoagulant condition, there was no significant difference of thrombotic events between two groups.

There is still no consensus regarding the administration of EPO currently. Zhao et al. [33] summarized the usage of EPO based on previous literatures. Most of the studies prefer to give 30,000 40,000 IU/w subcutaneously and the regime start 3-4 weeks before surgery. Considering the lack of patient compliance before hospitalization, we made some changes in the administration of $\mathrm{rHu}-\mathrm{EPO}$ during the hospital stay to make it more convenient and easily controlled compared with previous studies. In our study, 10,000 IU rHu-EPO was injected subcutaneously on the operation day and postoperative 1-7 days. The total dosage of rHu-EPO requirements in our regimen is less than previous studies. However, our results were consistent with previous reports and the regime could also be assessed as an alternative to reducing EPO dose requirements.

Several limitations of this study should be noted. First, a major limitation is the lack of a sufficiently large patient sample in our study but we found the false negative rate of VTE examined by TEG is extremely low. Second, we could not evaluate the long-term influence of $\mathrm{rHu}$ EPO on VTE as the treatment was too short, but the duration of anticoagulant therapy is much longer than the half-life of rHu-EPO subcutaneous injection. Finally, all participators received tranexamic acid and the oral anticoagulant rivaroxaban, which might have impacts on hematological parameters. However, the potential influence did not affect the conclusion because the same drugs were applicable to both groups.

\section{Conclusions}

Postoperative use of rHu-EPO and iron supplementation could improve the anemia-related parameters and reduce the requirement for $\mathrm{ABT}$ after THA without increasing the risk of VTE in the short term.

\section{Abbreviations \\ THA: Total hip arthroplasty; ABT: Allogenic blood transfusions; EPO: Erythropoietin; rHu-EPO: Recombinant human erythropoietin; VTE: Venous thromboembolism; DVT: Deep vein thrombosis; \\ TEG: Thrombelastography; Pre-op: Pre-operation; POD: Postoperative day; RBC: Red blood cell; Hb: Hemoglobin; HCT: Hematocrit; PLT: Platelet; FDP: Fibrin degradation products; PT: Prothrombin time; APTT: Activated partial thromboplastin time; FIB: Fibrinogen; TT: Thrombin time; INR: International normalized ratio; R: Reaction time; MA: Maximum amplitude; Cl: Coagulation index; FDA: Food and Drug Administration}

\section{Acknowledgements \\ This work has received the financial support from the National Natural Science Foundation of China (81902244), Key Program of Science and Technique Development Foundation in Jiangsu Province (BE2015627), Research Project of Jiangsu Provincial Health Department (H201528), Jiangsu Provincial Medical Youth Talent (QNRC2016801), and Xuzhou Science and Technology Innovation Project (KC19063).}

\section{Authors' contributions}

$R R, X Z$, and $K G$ designed the study and drafted the manuscript. $R R, C B$, and $\mathrm{LZ}$ performed the data collection and the statistical analysis. XCZ and ZZ screened the patients. SP and $\mathrm{CH}$ collected the information of patient samples. All authors read and approved the final manuscript. 


\section{Funding}

This work was supported by the National Natural Science Foundation of China (81902244), the Key Program of Science and Technique Development Foundation in Jiangsu Province (BE2015627), the Research Project of Jiangsu Provincial Health Department (H201528), the Jiangsu Provincial Medical Youth Talent (QNRC2016801), and Xuzhou Science and Technology Innovation Project (KC19063).

\section{Availability of data and materials}

There are available.

\section{Compliance with ethical standards}

The research plan was approved by the ethics committee of our hospital and all the participants singed informed consent.

\section{Ethics approval and consent to participate}

The research plan was approved by the ethics committee of our hospital and all the participants singed informed consent.

\section{Consent for publication}

All the patients in this study have given their informed consent for the article to be published.

\section{Competing interests}

The authors declare that they have no conflicts of interest.

Received: 6 September 2020 Accepted: 10 November 2020 Published online: 19 November 2020

\section{References}

1. Aggarwal VK, Elbuluk A, Dundon J, Herrero C, Hernandez C, Vigdorchik JM, Schwarzkopf R, lorio R, Long WJ (2019) Surgical approach significantly affects the complication rates associated with total hip arthroplasty. The bone \& joint journal 101-b (6):646-651. doi:https://doi.org/10.1302/0301620x.101 b6.bjj-2018-1474.r1.

2. Dailiana ZH, Papakostidou I, Varitimidis S, Liaropoulos L, Zintzaras E, Karachalios T, Michelinakis E, Malizos KN. Patient-reported quality of life after primary major joint arthroplasty: a prospective comparison of hip and knee arthroplasty. BMC musculoskeletal disorders. 2015;16:366. https://doi.org/10. 1186/s12891-015-0814-9.

3. Lasocki S, Krauspe R, von Heymann C, Mezzacasa A, Chainey S, Spahn DR. PREPARE: the prevalence of perioperative anaemia and need for patient blood management in elective orthopaedic surgery: a multicentre, observational study. Eur J Anaesthesiol. 2015;32(3):160-7. https://doi.org/10. 1097/eja.0000000000000202.

4. Newman JM, Webb MR, Klika AK, Murray TG, Barsoum WK, Higuera CA. Quantifying Blood Loss and Transfusion Risk After Primary vs Conversion Total Hip Arthroplasty. J Arthroplasty. 2017;32(6):1902-9. https://doi.org/10. 1016/j.arth.2017.01.038

5. Kotzé A, Carter LA, Scally AJ. Effect of a patient blood management programme on preoperative anaemia, transfusion rate, and outcome after primary hip or knee arthroplasty: a quality improvement cycle. Br J Anaesth. 2012;108(6):943-52. https://doi.org/10.1093/bja/aes135.

6. Saleh A, Small T, Chandran Pillai AL, Schiltz NK, Klika AK, Barsoum WK. Allogenic blood transfusion following total hip arthroplasty: results from the nationwide inpatient sample, 2000 to 2009. J Bone Joint Surg Am. 2014; 96(18):e155. https://doi.org/10.2106/jbjs.m.00825.

7. Perkins HA, Busch MP. Transfusion-associated infections: 50 years of relentless challenges and remarkable progress. Transfusion. 2010;50(10): 2080-99. https://doi.org/10.1111/j.1537-2995.2010.02851.x.

8. Rineau E, Chaudet A, Chassier C, Bizot P, Lasocki S. Implementing a blood management protocol during the entire perioperative period allows a reduction in transfusion rate in major orthopedic surgery: a before-after study. Transfusion. 2016;56(3):673-81. https://doi.org/10.1111/trf.13468.

9. Petis SM, Lanting BA, Vasarhelyi EM, Naudie DDR, Ralley FE, Howard JL. Is There a Role for Preoperative Iron Supplementation in Patients Preparing for a Total Hip or Total Knee Arthroplasty? J Arthroplasty. 2017;32(9):268893. https://doi.org/10.1016/j.arth.2017.04.029.

10. Wu YG, Zeng Y, Shen B, Si HB, Cao F, Yang TM, Pei FX. Combination of erythropoietin and tranexamic acid in bilateral simultaneous total hip arthroplasty: a randomised, controlled trial. Hip Int. 2016;26(4):331-7. https:// doi.org/10.5301/hipint.5000356.

11. Keating EM, Callaghan JJ, Ranawat AS, Bhirangi K, Ranawat CS. A randomized, parallel-group, open-label trial of recombinant human erythropoietin vs preoperative autologous donation in primary total joint arthroplasty: effect on postoperative vigor and handgrip strength. J Arthroplasty. 2007;22(3):325-33. https://doi.org/10.1016/j.arth.2006.11.002.

12. Tran DH, Wong GT, Chee YE, Irwin MG. Effectiveness and safety of erythropoiesis-stimulating agent use in the perioperative period. Expert Opin Biol Ther. 2014;14(1):51-61. https://doi.org/10.1517/14712598.2014. 858116

13. Stohlawetz PJ, Dzirlo L, Hergovich N, Lackner E, Mensik C, Eichler HG, Kabrna E, Geissler K, Jilma B. Effects of erythropoietin on platelet reactivity and thrombopoiesis in humans. Blood. 2000;95(9):2983-9.

14. Shi D, Xu X, Song K, Xu Z, Dai J, Chen D, Jiang Q. Comparison of venous thromboembolism after total hip arthroplasty between ankylosing spondylitis and osteoarthritis. BioMed Res Int. 2014;2014:712895. https://doi. org/10.1155/2014/712895.

15. Wu Z, Liu Z, Zhang W, Zhang W, Mu E. Risk of anticoagulation therapy in surgical intensive care unit patients predicted by thromboelastograph. Zhonghua wei zhong bing ji jiu yi xue. 2018;30(7):658-61. https://doi.org/10. 3760/cma.j.issn.2095-4352.2018.07.008

16. Wang C, Liu Q, Sun L, Dai G (2019) Application of thrombelastography in primary total knee and total hip replacement: a prospective 87 patients study. Blood coagulation \& fibrinolysis : an international journal in haemostasis and thrombosis 30 (6):281-290. doi:https://doi.org/10.1097/mbc 0000000000000839 .

17. Gonzalez-Porras JR, Colado E, Conde MP, Lopez T, Corral M. An individualized pre-operative blood saving protocol can increase preoperative haemoglobin levels and reduce the need for transfusion in elective total hip or knee arthroplasty. Transfusion Medicine. 2009;19(1):3542.

18. Suh YS, Nho JH (2016) A protocol avoiding allogeneic transfusion in joint arthroplasties. 136 (9):1213-1226. doi:https://doi.org/10.1007/s00402-0162516-7.

19. Bedair H, Yang J, Dwyer MK, McCarthy JC. Preoperative erythropoietin alpha reduces postoperative transfusions in THA and TKA but may not be costeffective. Clin Orthop Relat Res. 2015;473(2):590-6. https://doi.org/10.1007/ s1 1999-014-3819-z

20. So-Osman C, Nelissen RG, Koopman-van Gemert AW, Kluyver E, Pöll RG, Onstenk R, Van Hilten JA, Jansen-Werkhoven TM, van den Hout WB, Brand $\mathrm{R}$, Brand A. Patient blood management in elective total hip- and kneereplacement surgery (Part 1): a randomized controlled trial on erythropoietin and blood salvage as transfusion alternatives using a restrictive transfusion policy in erythropoietin-eligible patients. Anesthesiology. 2014;120(4):839-51. https://doi.org/10.1097/aln. 0000000000000134.

21. Buljan M, Nemet D, Golubic-Cepulic B, Bicanic G, Tripkovic B, Delimar D. Two different dosing regimens of human recombinant erythropoietin beta during preoperative autologous blood donation in patients having hip arthroplasty. Int Orthop. 2012;36(4):703-9. https://doi.org/10.1007/s00264011-1367-7.

22. Trkulja V. Treating anemia associated with chronic renal failure with erythropoiesis stimulators: recombinant human erythropoietin might be the best among the available choices. Medical hypotheses. 2012;78(1):157-61. https://doi.org/10.1016/j.mehy.2011.10.016

23. Thavarajah S, Choi MJ. The Use of Erythropoiesis-Stimulating Agents in Patients With CKD and Cancer: A Clinical Approach. Am J Kidney Dis. 2019; 74(5):667-74. https://doi.org/10.1053/j.ajkd.2019.04.022.

24. Li Y, Yin P, Lv H, Meng Y, Zhang L, Tang P. A meta-analysis and systematic review evaluating the use of erythropoietin in total hip and knee arthroplasty. Ther Clin Risk Manag. 2018;14:1191-204. https://doi.org/10. 2147/tcrm.s159134.

25. Fergusson DA, Hébert $P$. The health(y) cost of erythropoietin in orthopedic surgery. Can J Anaesth. 2005;52(4):347-51. https://doi.org/10.1007/ bf03016274.

26. Al Diab Al. Cancer-related venous thromboembolism: insight into underestimated risk factors. Hematology/oncology and stem cell therapy. 2010;3(4):191-5. https://doi.org/10.5144/1658-3876.2010.191.

27. Anaissie EJ, Coleman EA, Goodwin JA, Kennedy RL, Lockhart KD, Stewart CB, Coon SK, Bailey C, Barlogie B. Prophylactic recombinant erythropoietin 
therapy and thalidomide are predictors of venous thromboembolism in patients with multiple myeloma: limited effectiveness of thromboprophylaxis. Cancer. 2012;118(2):549-57. https://doi.org/10.1002/ cncr.26302.

28. Dunn CJ, Wagstaff AJ. Epoetin alfa. A review of its clinical efficacy in the management of anaemia associated with renal failure and chronic disease and its use in surgical patients. Drugs \& aging. 1995;7(2):131-56. https:/doi. org/10.2165/00002512-199507020-00007.

29. Feagan BG, Wong CJ, Kirkley A, Johnston DW, Smith FC, Whitsitt P, Wheeler SL, Lau CY. Erythropoietin with iron supplementation to prevent allogeneic blood transfusion in total hip joint arthroplasty. A randomized, controlled trial. Ann Intern Med. 2000;133(11):845-54. https://doi.org/10.7326/00034819-133-11-200012050-00008.

30. Van PY, Cho SD, Underwood SJ, Morris MS, Watters JM, Schreiber MA (2009) Thrombelastography versus AntiFactor Xa levels in the assessment of prophylactic-dose enoxaparin in critically ill patients. The Journal of trauma 66 (6):1509-1515; discussion 1515-1507. doi:https://doi.org/10.1097/TA. 0b013e3181a51e33.

31. Pekelharing J, Furck A, Banya W, Macrae D, Davidson SJ. Comparison between thromboelastography and conventional coagulation tests after cardiopulmonary bypass surgery in the paediatric intensive care unit. Int J Lab Hematol. 2014;36(4):465-71. https://doi.org/10.1111/ijlh.12171.

32. Cotton BA, Minei KM, Radwan ZA, Matijevic N, Pivalizza E, Podbielski J, Wade CE, Kozar RA, Holcomb JB (2012) Admission rapid thrombelastography predicts development of pulmonary embolism in trauma patients. J Trauma Acute Care Surg 72 (6):1470-1475; discussion 1475-1477. doi:https://doi.org/ 10.1097/TA.0b013e31824d56ad.

33. Zhao Y, Jiang C, Peng H, Feng B, Li Y, Weng $X$. The effectiveness and safety of preoperative use of erythropoietin in patients scheduled for total hip or knee arthroplasty: A systematic review and meta-analysis of randomized controlled trials. Medicine (Baltimore). 2016;95(27):e4122. https://doi.org/10. 1097/md.0000000000004122

\section{Publisher's Note}

Springer Nature remains neutral with regard to jurisdictional claims in published maps and institutional affiliations.

Ready to submit your research? Choose BMC and benefit from:

- fast, convenient online submission

- thorough peer review by experienced researchers in your field

- rapid publication on acceptance

- support for research data, including large and complex data types

- gold Open Access which fosters wider collaboration and increased citations

- maximum visibility for your research: over $100 \mathrm{M}$ website views per year

At $\mathrm{BMC}$, research is always in progress.

Learn more biomedcentral.com/submissions 